\title{
Restauração, Respeito e Inclusão como caminho para a paz
}

\author{
Paulo Roberto Loyolla Kuhlmann \\ Suerda Gabriela Ferreira de Araújo
}

TUTU, Desmond. Deus não é cristão e outras provocações. Rio de Janeiro: Thomas Nelson Brasil, 2012. [Trad. Lilian Jenkino].

Antes de o leitor pensar que Deus não é cristão e outras provocações seja uma "heresia", Desmond Tutu o convida a se juntar às pessoas de fé para que se torne colaborador de Deus no mundo. Além de ser o arcebispo da Cidade do Cabo, ele lutou contra o regime apartheid, presidiu a Comissão da Verdade e Reconciliação (CVR) da África do Sul e foi laureado com o Nobel da Paz em 1984. Desmond Tutu aborda

\footnotetext{
Paulo Roberto Loyolla Kuhlmann Professor do Programa de Graduação e Pós-Graduação em Relações Internacionais, da Universidade Estadual da Paraíba (UEPB). Coordenador do Grupo de Estudos de Paz e Segurança Mundial (GEPASM/UEPB). prlkuhlm@gmail.com.
}

Suerda Gabriela Ferreira de Araújo Graduanda em Relações Internacionais pela Universidade Estadual da Paraíba (UEPB), membro do Grupo de Estudos de Paz e Segurança Mundial (GEPASM/ UEPB).

suerdagabriela@gmail.com. temáticas paradigmáticas por um viés distinto da pastoralidade, de modo a desprender-se dos dogmas e tabus morais e rumar ao serviço para os marginalizados, atrelado à compaixão, à justiça e ao perdão. Isso implica defrontar-se com três fundamentalismos - o ideológico, o político e o religioso -, possibilitando, por consequência, a tolerância e a fraternidade a outrem. Essa obra é a reflexão da ação de Tutu, a partir das várias reuniões privadas com líderes das mais diversas estirpes e identificações, além de entrevistas e falas públicas de onde advêm as diversas provocações.

Esse livro está dividido em quatro partes. Na primeira, Advogado da Tolerância e do Respeito, Tutu inicia tratando sobre o relacionamento da fé de um indivíduo para com a fé 
do próximo, como ponto fundamental para se chegar à raiz de um conflito. Compreender que o contexto exerce forte influência na formação particular dos indivíduos, sendo determinante no seu modo de perceber a realidade, contribui para desmistificar o monopólio da verdade alicerçada na fé individual e possibilita a crença na igualdade implícita entre todas as religiões, quando explicitamente são distintas. Para Tutu, a noção patrimonial que as religiões têm de Deus não se sustenta.

Posteriormente, aborda a noção da coconstrução do ser humano, bem como sua independência de posses materiais ou status quo. A ênfase está na ideia de ubuntu, que atrela a natureza e a razão de nossa existência ao pertencimento à comunidade humana. A essência do ubuntu está na relação de aprendizagem entre humanos, ao passo que o individualismo e a indiferença a tal relacionamento é a causa de perda de humanidade. O que se põe em questão neste capítulo é o ser, em que a necessidade imposta de ser algo sobrepujou-se ao ser humano.
Em seguida, Tutu se posiciona a favor da justiça restauradora. Ele está convicto quanto à cura só se efetivar a partir do perdão das vítimas em relação aos ofensores, visto que, em algum momento, a reconciliação se fez necessária entre os humanos. Aponta que o perdão não pressupõe esquecimento: ambos são díspares em suas significações, de modo que o primeiro é prerrogativa do caminho da cura e do reconhecimento de que algo ocorreu e precisa ser confrontado, enquanto o outro pode levar à alienação. Para Tutu, só quem experimentou o sofrimento pode vir a perdoar, ao mesmo tempo em que o ofensor solícito do perdão só o requer verdadeiramente quando pratica o arrependimento, a confissão, a restituição e a restauração. A partir do aceite de ambas as partes, a confrontação e a recuperação da humanidade tomam lugar e um futuro de paz torna-se possível.

Em 1991, quando em Benin, Desmond Tutu incentivou que as premissas do ubuntu fossem projetadas mundialmente nos sistemas judiciários, voltando sua atenção principalmente à restauração de boas relações 
(justiça restaurativa) em lugar de punição e castigo (justiça retributiva). Tutu também propôs, em 1994, durante o genocídio em Ruanda, que o círculo da violência fosse rompido. Foi a humanidade advinda do ubuntu que também possibilitou a criação da CVR, da qual Tutu foi presidente, durante o governo de Nelson Mandela. Ao tratar das grandes violações aos direitos humanos, no apartheid, anistiou os ofensores e, ainda, criou políticas de reparação e reabilitação das vítimas e suas famílias.

Em seguida, Tutu conclama a celebrarmos a diferença. Afinal, a diversidade de órgãos existentes no corpo humano é o que o torna um organismo e, do contrário, o desastre se apresenta juntamente com a instabilidade e a insegurança. Tudo isso fica mais evidente quando Tutu defende a inclusão de gays e lésbicas no ambiente religioso e na sociedade, sem que para isso sejam celibatários (como recomenda a igreja anglicana), e posiciona-se contrariamente à proibição das mulheres para o episcopado. Não se pode penalizar alguém em relação a algo que não pode controlar, como é o caso de raça, sexualidade e gênero. É interessante notar que Tutu realiza a extrapolação dessas mesmas premissas nas esferas domésticas e internacionais, quando aponta que países em desenvolvimento vivem em cativeiro devido a dívidas externas contraídas com países desenvolvidos.

Avançando para a segunda parte do livro, Defensor Internacional da Justiça, Desmond Tutu mantém O ardor da sua crítica, apontando que a conquista do poder pelos negros e o fim do apartheid não o fizeram descansar. Ele argumenta que a liberdade é mais acessível que a repressão, dentro de um contexto pós-libertação das nações africanas, mas é contundente em apontar as falhas do novo sistema democrático multipartidário sul-africano. Ele reitera esse tema quando aborda a preocupação com as necessárias características de um líder, como o altruísmo abnegado e a integridade, com o intuito de demonstrar que os anos de luta sul-africana estão despencando frente às violações morais do governo e do aparente esquecimento da população. Seu foco está no governante Jacob Zuma e as diversas acusações 
de estupro, corrupção, lavagem de dinheiro e fraude.

Sobre as negociações de paz na Irlanda, em 1991, Tutu, por meio de discurso televisionado em Dublin, afirmou que o diálogo não poderia, em hipótese alguma, deixar de ser inclusivo, visto que a paz só se torna possível quando todos sentem-se representados legitimamente e ouvidos. Para Tutu, esperanças de sucesso de acordos firmados são postas em descrença por haver partes que não os reconhecem como legítimos, uma vez que foram excluídas das decisões. É preciso observar as condições prévias para o diálogo, visto que, quanto mais pré-condições houver, mais haverá vulnerabilidades nas negociações e, consequentemente, o acordado poderá ser questionado pelas partes, tanto as incluídas quanto aquelas que destas se servirão. Esta postura de Tutu influenciou no acordo da Sexta-Feira Santa, em 1998.

Sobre o conflito israeli-palestino, Tutu se oferece como mediador juntamente com Eli Wiesel (ambos laureados com Nobel da Paz), a fim de lutar pela igualdade, justiça e reconciliação dos povos, cujos elementos poderão construir a paz verdadeira. Há uma forte distinção entre governo de Israel e povo judeu. Este último faz parte da formação de Tutu na qualidade de pastor. Relembrando a história dos judeus, Tutu afirma que um país que experimentou a expatriação não deveria aspirar expatriar outros. Ao mesmo tempo, critica a Palestina por almejar a destruição de Israel e não reconhecer o seu direito de Estado independente. Para ele, a busca de um Estado soberano poderá obter sucesso quando ambos, palestinos e israelenses, ouvirem suas angústias e clamores. Critica ainda o governo de Israel por colaborar com o regime de apartheid sul-africano, principalmente na área de tecnologia militar e nuclear, não cooperando com o embargo da comunidade internacional contra a África do Sul racista, um meio possível de alicerçar uma transformação pacífica no país. Por tal posicionamento, Desmond Tutu é apontado por muitos como antissemita.

A terceira parte, A Voz dos Sem-voz na África do Sul, revela a linguagem como condicionante humana. O "não branco" ou "não é isto ou aquilo" inferioriza o negro e, por senso 
comum, ele assim passa a se perceber como sendo de um nível aquém dos brancos. Classificações determinadas pelos brancos ou, mais especificamente, pelo Ocidente ganham cunho universal. Em seguida, Tutu contrapõe essa premissa debatendo a teologia negra. A compreensão dos mistérios da fé é dada de modo distinto, assim como a teologia é percebida segundo quem somos. Interpretações da teologia cristã branca, qualificando anjos brancos como bons e anjos negros como maus, não condizem às realidades de cristãos negros. Enfoca-se na teologia negra tendo em vista a variabilidade das circunstâncias e a totalidade do negro como sendo pontos cruciais, todavia, almejando a libertação plena de toda pessoa humana.

Na sequência, o discurso de Tutu, proferido em 1978, a uma plateia branca apresenta a verticalidade divina fundamental em sua vida como finalidade de um relacionamento autêntico com o humano. Esse imperativo cristão leva Tutu ao âmbito sociopolítico e econômico, nos quais espera que todos os crentes no evangelho se engajem, visto que o julgamento de Deus abrangerá toda a conduta dos cristãos. Em consequência desse compromisso, Tutu expõe preocupação e desgosto ao primeiro-ministro Pieter Willem Botha quanto ao processo de realocação dos negros sul-africanos, ocorrido em 1979, que os tratou como menos que seres humanos e, por isso, solicita a suspensão do reassentamento.

Na quarta parte, $A$ Consciência da África do Sul é trazida aos debates, Tutu aponta as causas da violência, no período de soltura de Mandela até sua ascensão ao governo. Para ele, as causas foram os modos desaprováveis utilizados pelas forças de segurança; a privação sociopolítica e econômica; o sistema de trabalho migratório e os hostels separados por sexo; a rivalidade política; a coação e a intimidação quanto a participação em movimentos e boicotes. Entretanto, a responsabilidade pós-regime apartheid também pertence à população, que aparenta perda de humanidade. No intuito de romper tal alienação, Tutu sugere que a cultura da tolerância seja adquirida; as organizações políticas estimulem um código de parâmetros 
e condutas mínimas; todos relação do governo atual com os grupos sejam desarmados; a igreja está em consonância, ocorra a transformação da mas esta última não pode se polícia em uma força de paz deixar cooptar. A isenção crítiverdadeira; discursos violentos ca é a postura necessária para sejam proibidos; as municipalidades se organizem em prol de despoluir as townships; e haja orações pela paz, pela África, pelos líderes e pelas crianças.

Posteriormente, num cenário em que Mandela já havia ascendido ao poder, Tutu critica o governo por ainda manter em funcionamento as indústrias bélicas do período do apartheid. Para Tutu, os únicos inimigos situam-se internamente, os quais são a pobreza, o crime,

a doença e a corrupção, e a um religioso.

Para além de uma abordagem dos discursos de Tutu, que seguem uma cronologia que vai do apartheid à pós-democracia da África do Sul, essa obra contribui para o desenvolvimento de uma cultura de paz e uma percepção de que é possível alcançar, gradativamente, uma cultura do diálogo, da não-violência e do respeito mútuo, dada a vinculação complexa entre o local e o global. 